\title{
Characterization of conditions and determination of practical tips for mtDNA level estimation in various human cells*
}

\author{
Paulina Jędrak ${ }^{\bowtie}$, Natalia Sowa\#, Sylwia Barańska\#\# and Grzegorz Węgrzyn \\ Department of Molecular Biology, University of Gdańsk, Gdańsk, Poland
}

Determination of mtDNA copy number in the cell is crucial to understand many cellular processes. Recently, the number of studies with the use of mitochondrial DNA (mtDNA) content as the determinant of mitochondrial abnormalities increased greatly and is still growing, therefore, optimization of technical conditions for this analysis is crucial. Despite using similar laboratory protocols, some results cannot be compared between research centers, thus causing discrepancies in the assessment of mtDNA content. The aim of this work was to test which conditions of biological sample collection and storage affect estimation of mtDNA level relative to the nuclear DNA (nDNA) in the blood samples and dermal fibroblasts. We found that the time and temperature of sample storage, as well as the type of the blood sample (whole blood or leukocytes) influence the estimate of mtDNA/nDNA ratio in the blood. In the case of dermal fibroblasts collected from healthy control and Huntington disease patients, our data indicate that the passage number of cells is essential to obtain reliable results.

Key words: mtDNA level, leukocytes, fibroblasts, qPCR methodology, Huntington disease

Received: 17 August, 2017; revised: 13 November, 2017; accepted: 14 November, 2017; available on-line: 15 December, 2017

*Preliminary report on this topic was presented at the $7^{\text {th }}$ World Congress on Targeting Mitochondria in Berlin (2016)

"Current affiliation: Department of Medical Biology and Genetics, University of Gdańsk, Wita Stwosza 59, 80-308 Gdańsk, Poland \#Current affiliation: Department of Bacterial Molecular Genetics, University of Gdańsk, Wita Stwosza 59, 80-308 Gdańsk, Poland e-mail: paulina.jedrak@biol.ug.edu.pl

Abbreviations: mtDNA, mitochondrial DNA; nDNA, nuclear DNA qPCR, real-time quantitative PCR; HD, Huntington disease

\section{INTRODUCTION}

The major role of mitochondria is to generate ATP through oxidative phosphorylation (OXPHOS) (Nicholls, 2002; Wojtczak \& Zabocki, 2008). Mitochondria are also involved in many other cellular processes, like cell proliferation, energetic metabolism, apoptosis, calcium homeostasis and regulation of signal cascades, which make the mitochondria extremely important organelles in the cell. Human mitochondria contain DNA (mtDNA) as a double-stranded $16.6 \mathrm{~kb}$ molecule which encodes 13 proteins (subunits of the respiratory chain), 22 tRNAs and 2 rRNAs (crucial for protein synthesis) (Anderson $e t$ al., 1981). The mtDNA copy number varies in different cell types within the same individual, as well as in the same tissue type among the population. Besides specific energy demand, many other factors, like development, aging, health conditions, smoking cigarettes and endurance training, may also have an impact on mtDNA level (Holloszy \& Coyle, 1984; Battersby \& Moyes, 1998; Lee et al., 2000; Masayesva et al., 2006; Morten et al., 2007).

Proper determination of mtDNA copy number in the cell is important for understanding many cellular processes, and changes in mtDNA level can correlate with a wide range of human diseases like autism, heart failure, cancer, diabetes and neurodegenerative diseases (Chinnery \& Samuels, 1999; Wallace, 2010; Greaves et al., 2012; Chen et al., 2015; Huang et al., 2016; Pyle et al., 2016; Jedrak et al., 2017). For mtDNA level estimation, real-time quantitative PCR (qPCR) is used to determine the ratio of mitochondrial genome to the nuclear DNA (Kalinowski et al., 1992; Zhang et al., 1994; Meissner et al., 2000; Chabi et al., 2003). Despite using the same method, many data that are available cannot be compared between research centers due to the use of different laboratory protocols, which may affect the mtDNA estimate. This causes discrepancies in the determination of $\mathrm{mtDNA}$ content in various diseases, like the Huntington disease (HD) (Chen et al., 2007; Liu et al., 2008; Petersen et al., 2014; Jedrak et al., 2017), or diabetes (Lee et al., 1998; Malik et al., 2009; Weng et al., 2009; Wong et al., 2009), and leads to an inability to clearly assess the mtDNA level in these disorders.

Due to the hypothesis that mtDNA content could be a biomarker of mitochondrial dysfunction (Malik \& Czajka, 2013), it seems it is crucial to establish a common protocol of mtDNA level quantification. Although there are several published data on some of the factors that may impact proper mtDNA amount estimation (summarized in Table S1 at www.actabp.pl), there are still numerous issues in that quantification which need to be solved. The study presented here focuses on blood samples and cell cultures (fibroblasts) due to the ethical matters and facility of the use of these materials as potential biomarkers of various diseases. Blood and fibroblast collection from healthy persons and patients is not as greatly burdensome as other tissues, thus, these biological materials are the first choice in the search for non-invasive disease biomarkers. Furthermore, mtDNA level evaluation protocol from tissue biopsy is well described in the literature (Grady et al., 2014; GonzalezHunt et al., 2016).

This study concerns the appropriate methodology of mtDNA level examination in blood cells and fibroblasts which includes several factors affecting the proper $\mathrm{mtDNA}$ level investigation, like the time and conditions of blood sample storage, blood sample type used as a material (whole blood or leukocytes) and the fibroblasts' passage number. 


\section{MATERIALS AND METHODS}

Blood sample storage conditions and DNA isolation. Human blood from 5 volunteers was collected into four tubes (filled with $4 \mathrm{ml}$ EDTA), in duplicate, in the intervening period (day 0 and day 7). No subject changed their lifestyle during the 7 day period between blood sampling. Each sample has been stored under different conditions until DNA isolation procedure. The following conditions of sample storage before DNA extraction were selected: (i) at most, 3 hours at room temperature; (ii) 24 hours at $4^{\circ} \mathrm{C}$; (iii) 3 days at $-20^{\circ} \mathrm{C}$; (iv) 7 days at $-80^{\circ} \mathrm{C}$. A research process flow chart is shown in Fig. 1.

After these periods, the blood sample was divided into 2 samples, from one of which leukocytes were separated by LIZ-MIX, as reported previously (Jedrak et al., 2017). Total DNA was extracted from $200 \mu \mathrm{l}$ of whole blood or leukocyte pellet suspended in the PBS buffer (SigmaAldrich Co. LLC., St. Louis, USA) using QIAamp ${ }^{\circledR}$ DNA Mini (QIAGEN, Hilden, Germany), following the manufacturer's protocol.

Cell cultures and DNA isolation. Fibroblasts were cultured in DMEM (Thermo Fisher Scientific Inc., Paisley, UK), supplemented with 10\% FBS (Thermo Fisher Scientific Inc., Paisley, UK), and 1\% antibiotic/antimycotic solution (Sigma-Aldrich Co. LLC., St. Louis, USA), and maintained under standard conditions. DNA isolation was performed from fibroblasts: 6 cell lines collected from healthy volunteers and 6 cell lines collected from the Huntington disease patients. DNA isolation was conducted at passage $9^{\text {th }}$ and $15^{\text {th }}$ for each cell line by QIAamp ${ }^{\circledR}$ DNA Mini (QIAGEN, Hilden, Germany), following the manufacturer's protocol.

Quantitative polymerase chain reaction. Quantitative PCR was used to determine the relative mtDNA copy number in the whole blood, leukocytes and fibroblasts, as an estimation of threshold cycle (Ct) of nuclear and mitochondrial single copy genes. The primer pair used in this study is presented in Table 1. The procedure was carried out using LightCycler ${ }^{\circledR} 480$ SYBR Green I Master (La Roche Ltd. Basel, Switzerland), as described previously (Jedrak et al., 2017). The mtDNA copy number was calculated using the formula:

$2^{\Delta \mathrm{Ct}}\left(\Delta \mathrm{Ct}=\mathrm{Ct}_{\text {(nuclear gene) }}-\mathrm{Ct}_{\text {(mitochondrial gene) }}\right)$

as the relative ratio of $\mathrm{mtDNA}$ to the nuclear DNA in whole blood, leukocytes and fibroblasts.

Statistical analysis. Statistical analyses were performed using Statistica 12. Due to high variation in
mtDNA amount among individuals, raw data were log transformed. Normality of distribution was tested with the Shapiro-Wilk tests, while homogeneity of variance was verified by the Levene test. To compare results from the two blood donations, "repeated measures" $t$-test was used. When 2 independent groups were compared depending on the data distribution and homogeneity of variance, the t-test or U Mann-Whitney test were performed. To analyze more than 2 groups, ANOVA with sensitive post-hock NIR (least significant differences) was used.

Bioethical consent of participants. The study was approved by the local Ethics Committee of the Medical University of Gdansk (NKEBN/254/2011 and NKE$\mathrm{BN} / 254-431 / 2012$ ) and was conducted according to the tenets of the Helsinki Declaration. Written informed consents were obtained from participants prior to the study procedure.

\section{RESULTS}

\section{Reproducibility of the mtDNA level calculation in samples collected at 7 day time interval}

mtDNA amount was determined in samples collected from each volunteer on two separate days (day 0 and day 7). We intended to verify if mtDNA amount in the blood changes within a short time period (7 days) depending on the sample storage conditions. There was no significant difference in mtDNA level between blood samples derived from the same person in the 7 day interval, regardless of the blood sample type used (whole blood or leukocytes), except when blood was stored for 3 days at $-20^{\circ} \mathrm{C}$ ("repeated measures" $t$-test). Under these conditions, mtDNA level changed in time regardless of the blood sample type (Fig. S1, at www.actabp. $\mathrm{pl})$. These results indicate that in samples from healthy people, during the short time period, the mtDNA level is constant except when the sample was stored at $-20^{\circ} \mathrm{C}$. Therefore, these sample storage conditions were not considered in further analysis.

\section{Influence of the use of different blood sample types on mtDNA content}

Total DNA was extracted from the whole blood, as well as leukocytes of each sample. Significant differences in $\mathrm{mtDNA} / \mathrm{nDNA}$ ratio between DNA extracted from whole blood and leukocytes were observed in non-frozen blood samples when DNA was extracted after $3 \mathrm{~h}$

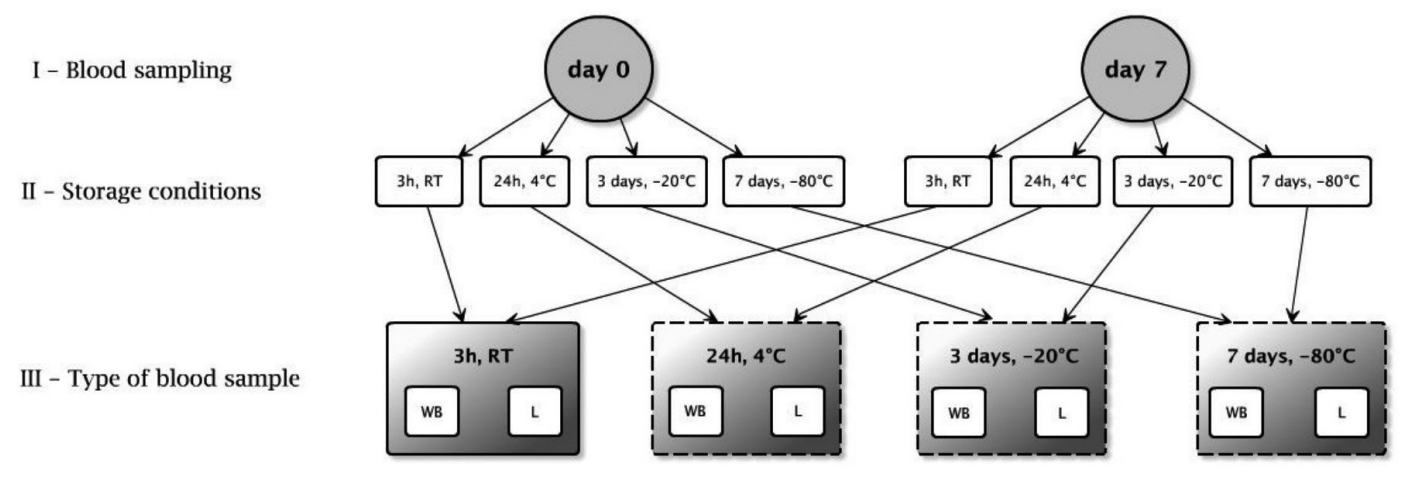

Figure 1. Research process flow chart.

Samples were taken from each volunteer at two separate days, day 0 and day 7 (I - Blood sampling) and have been stored under four different conditions before DNA isolation (II - Storage conditions). Total DNA was extracted from whole blood and the leukocytes (III Type of blood sample). The dotted lines indicate conditions which we discourage for blood sample storage. 
Table 1. Primer sequences. $\mathrm{mt}$ - mitochondrial, $\mathrm{n}$ - nuclear, F/R - forward/reverse primer

\begin{tabular}{|c|c|c|c|}
\hline $\begin{array}{l}\text { Gene symbol } \\
\text { (origin) }\end{array}$ & Reference & Primer sequence $\left(5^{\prime}-3^{\prime}\right)$ & Amplicon size (bp) \\
\hline $16 \mathrm{~S}$ rRNA (mt) & (Jedrak et al, 2017) & $\begin{array}{l}\text { F: CGAAAGGACAAGAGAAATAAGG } \\
\text { R: CTGTAAAGTITAAGIITATGCG }\end{array}$ & 151 \\
\hline $\begin{array}{l}\beta \text {-hemoglobin } \\
\text { (n) }\end{array}$ & & $\begin{array}{l}\text { F: CAACTTCATCCACGTTCACC } \\
\text { R: GAAGAGCCAAGGACAGGTA }\end{array}$ & 267 \\
\hline
\end{tabular}

and $24 \mathrm{~h}$. Under those conditions, mtDNA amount was higher when DNA was extracted from whole blood than from leukocytes (Fig. 2a).

\section{Influence of blood sample storage conditions on mtDNA level}

We aimed to check whether blood sample storage conditions may have an impact on mtDNA level. Due to differences between mtDNA amount depending on the blood sample type, the results obtained from this analysis should be discussed separately for DNA samples extracted from whole blood and leukocytes (Fig. 2b).

When DNA was isolated from whole blood, statistically significant changes in mtDNA amount were present between samples isolated after $3 \mathrm{~h}$ and $24 \mathrm{~h}$, however, this difference was not observed in the case of leukocytes. For both sample types, significant differences in mtDNA amount were detected after freezing the samples at $-80^{\circ} \mathrm{C}$ and when DNA isolation was conducted up to $3 \mathrm{~h}$ after blood donation. Earlier analysis showed that blood storage for 3 days at $-20^{\circ} \mathrm{C}$ should be excluded, however, it is important to note that mtDNA level in frozen samples (either at $-20^{\circ} \mathrm{C}$ or $-80^{\circ} \mathrm{C}$ ) was comparable regardless of using whole blood or leucocytes as
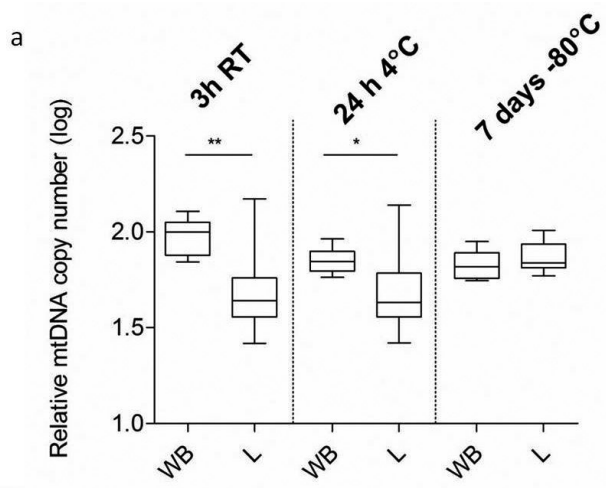

b

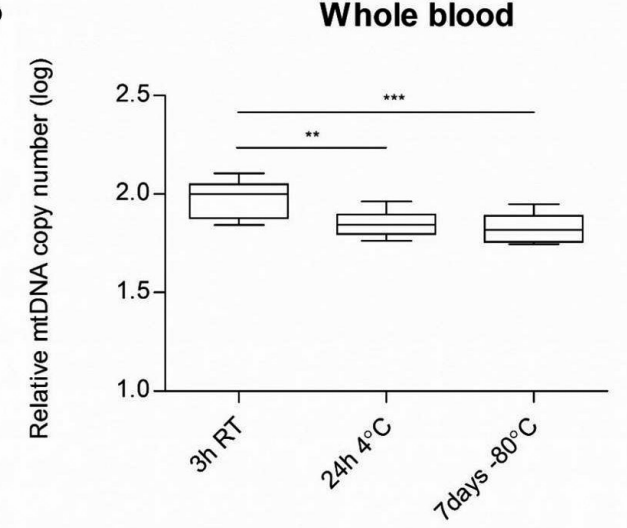

\section{passage number on mtDNA level estimation}

the starting material. It testifies to the fact that freezing of the sample, irrespective of temperature and storage time, significantly affects the mtDNA level estimation and can disrupt analysis of results.

Influence of fibroblast

Total DNA isolation was performed from cells at the 9th and 15th passages. There were no significant differences in $\mathrm{mtDNA}$ amount in healthy individuals regardless of the number of passages at which DNA was extracted. However, there was a significant increase in mtDNA level in HD patients between the 5th and 9th, as well as the 5th and 15th passage (Fig. 3). It appears that mtDNA level in cells from HD patients can change when culturing cells for several passages, and can reach the level typical for healthy subjects.

\section{DISCUSSION}

Our aim was to investigate the impact of blood sample type used for the DNA extraction (whole blood or leukocytes), blood sample storage conditions and influence of passage number of fibroblasts on mtDNA level estimation.

First, we wanted to test whether the obtained results are reproducible after a 7 day period, depending on the sample storage conditions. There was no change in 
Control

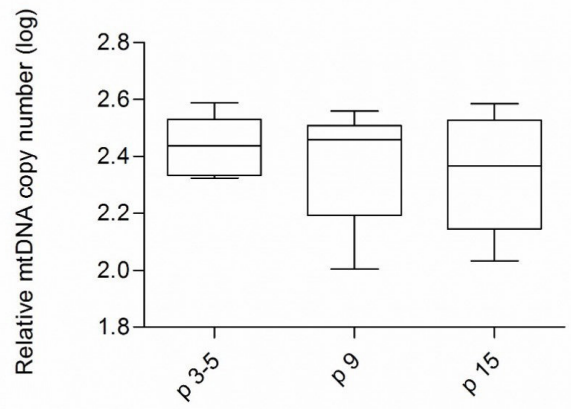

HD

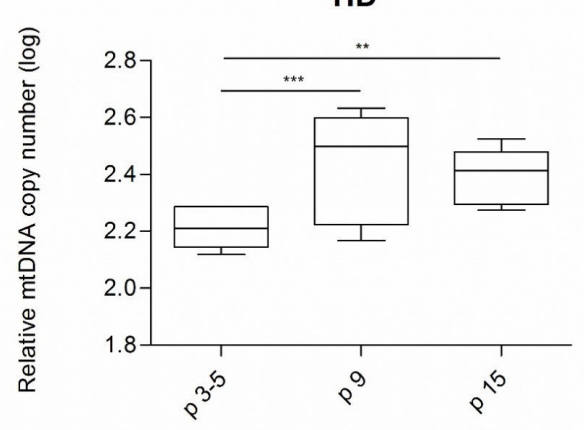

Figure 3. Influence of fibroblast passage number on mtDNA content evaluation. The Mann Whitney test on log-transformed data: ${ }^{*} p<0.05,{ }^{* *} p<0.01,{ }^{* * *} p<0.001$.

mtDNA level estimated in the blood sample collected from the same person, except when blood was stored for 3 days at $-20^{\circ} \mathrm{C}$. It seems that freezing a blood sample at $-20^{\circ} \mathrm{C}$ and/or its subsequent de-freezing may influence mtDNA and/or nDNA degradation in an irreproducible manner. This might be due to cell damage when they are thawed, which causes leakage of $\mathrm{mtDNA}$, nDNA and enzymes, including nucleases, and unpredictable efficiency of mtDNA and $\mathrm{nDNA}$ cleavage.

Next, we tested whether the blood sample type from which DNA was isolated - whole blood or leukocytes, may impact mtDNA content evaluation. Our results corroborate those reported previously (Andreu et al., 2009) and show that mtDNA level is higher when DNA extraction was performed from whole blood. This can be caused by the presence of platelets in whole blood, as well as a possible extracellular nDNA and ntDNA release in the serum and plasma (Chiu et al., 2003; LO, 2006). Due to those reasons, we recommend using leucocytes as a sample for DNA extraction. These results also indicate that conclusions drawn from previously conducted experiments should be sorted depending on the material used for DNA isolation.

We tested whether time and temperature of blood sample storage may have an impact on mtDNA amount calculation. Our results show that freezing of the sample before DNA isolation significantly affects mtDNA level compared to the samples for which the extraction started up to $3 \mathrm{~h}$ after blood sampling, regardless of the blood sample type (whole blood or leukocytes). This observation suggests that freezing of the blood has adverse effects and the use of frozen blood (whether at $-20^{\circ} \mathrm{C}$ or $-80^{\circ} \mathrm{C}$ ) for this type of analysis can lead to false conclusions. In terms of not frozen material, the significant differences in mtDNA amount between samples isolated up to $3 \mathrm{~h}$ and $24 \mathrm{~h}$ after collection were observed in whole blood. However, due to a small group of volunteers (5 subjects), we cannot exclude that the $24 \mathrm{~h}$ time period before DNA isolation may be also crucial for samples where DNA was extracted from leukocytes. One should note that conducting DNA isolation from blood collected at a medical center is often not possible, and transport of the samples to a research institution is associated with the passage of time which can be crucial for proper $\mathrm{mtDNA}$ content estimation. Longer storage time of the blood sample may result in a different degradation of both, the nuclear and mitochondrial DNA, and lead to altered results.

To check the impact of passage number on mtDNA level quantification, we performed DNA isolation from 6 fibroblast cell lines taken from HD patients and 6 control cell lines (which were used in our previous study) at higher passages - 9th and 15th, and conducted quantification (Jedrak et al., 2017). We decided to use HD fibroblast to check whether mtDNA level may change during passaging cells collected from patients. Our result showed that there were no differences in mtDNA levels between healthy volunteers in the DNA extracted from cells at the 9th and 15th passages when compared to results obtained from the 5th passage. (Jedrak et al., 2017). The median level of mtDNA in control cells was not changed significantly during passaging (passage $5=2.367$; passage $9=2.459$; passage $15=2.340$ ), however, in $\mathrm{HD}$ cells the mtDNA amount increased during culturing, and the median value approached a value characteristic for healthy subjects, (passage $5=2.255$; passage 9 $=2.2498$; passage $15=2.398)$. Our recent studies show that the reduced mtDNA level in $\mathrm{HD}$ patients observed in the fresh material was blurred with increasing passages.

\section{CONCLUSIONS}

Our practical knowledge of the limitations associated with the collection of biological material from patients who are often in the advanced stage of the disease led

Table 2. Practical guidelines for using a blood sample and cell lines as a material for mtDNA level estimation.

\begin{tabular}{|c|c|}
\hline Methodical issue & Recommendations \\
\hline $\begin{array}{l}\text { Time between the collection of the blood sample until the } \\
\text { beginning of DNA isolation }\end{array}$ & Max $3 \mathrm{~h}$ \\
\hline Temperature conditions for storage of samples & Room temperature ( $\max 3 \mathrm{~h}$ ), avoid freezing the sample \\
\hline DNA extraction method & Silica column method \\
\hline Cell type (whole blood/leukocytes) & Note the difference between cell type (leukocytes are recommended) \\
\hline Passage number at which DNA should be isolated from cells & The lowest possible passage $(<5)$ \\
\hline
\end{tabular}


us to attempt to design a practical guideline to help researchers to achieve optimal blood sampling protocol. Due to high variation in mtDNA amount among individuals (including healthy population) we recommend that correlation of mtDNA level with the severity of different types of diseases should be performed with as large study group as possible. Choosing a fast and easy method of total DNA isolation (for example a column method) seems to be the most appropriate. This is also supported by the reports showing that the use of the column method to isolate total DNA does not disrupt the mitochondrial/nuclear genome ratio (Andreu et al., 2009). We propose that for an accurate mtDNA content quantification, immediate DNA isolation from the blood sample is required. However, for practical purposes, we postulate that time of $3 \mathrm{~h}$ since blood collection to DNA isolation initiation can result in adequate mtDNA quantification and is sufficient to transport the sample to a given research institution and perform the procedure. We do not recommend freezing of blood samples under any conditions. Moreover, the type of blood sample (whole blood or leukocytes) may have a significant influence on results and may be one of the reasons for problems with comparing results between research centers; therefore, researchers should keep this in mind when planning their study. For researchers intending to use fibroblasts as a material to detect potential changes in the mtDNA level in various diseases, we recommend that DNA isolation should be performed at the lowest possible passage, since the disease phenotype mtDNA level may lose its characteristic value during cell culturing under laboratory conditions.

In summary, we have proposed practical tips for using the blood sample and cell lines as a material for mtDNA level estimation (summarized in Table 2). Moreover, we believe these recommendations will also help researchers in proper planning of the material collection since our study shows that this is an extremely important step in the analysis.

\section{Competing interests}

The authors declare that they have no conflict of interest.

\section{Acknowledgements}

We would like to thank Professor Janusz Limon for providing skin samples and all patients and healthy volunteers for participation in this study.

\section{Acknowledgments for financial support}

This work was supported by the National Science Center (Poland), project grant No. 2015/17/N/ NZ2/04267 and 2011/03/B/NZ2/01422

\section{REFERENCES}

Anderson S, Bankier AT, Barrell BG, de Bruijn MH, Coulson AR, Drouin J, Eperon IC, Nierlich DP, Roe BA, Sanger F, Schreier PH, Smith AJ, Staden R, Young IG (1981) Sequence and organization of the human mitochondrial genome. Nature 290: 457-465. http:// doi.org/10.1038/290457a0

Andreu AL, Martinez R, Marti R, García-Arumí E (2009) Quantification of mitochondrial DNA copy number: Pre-analytical factors. Mitochondrion 9: 242-246. http://doi.org/10.1016/j.mito.2009.02.006

Battersby BJ, Moyes CD (1998) Influence of acclimation temperature on mitochondrial DNA, RNA, and enzymes in skeletal muscle. Am J Physiol 275: R905-R12.

Chabi B, Camaret BM de, Duborjal H, Issartel J-P, Stepien G (2003) Quantification of mitochondrial DNA deletion, depletion, and overreplication: application to diagnosis. Clin Chem 49: 1309-1317. http://doi.org/10.1373/49.8.1309

Chen CM, Wu YR, Cheng ML, Liu JL, Lee YM, Lee PW, Soong BW, Chiu DTY (2007) Increased oxidative damage and mitochondrial abnormalities in the peripheral blood of Huntington's disease patients. Biochem Biophys Res Commun 359: 335-340. http://doi. org/10.1016/j.bbrc.2007.05.093

Chen S, Li Z, He Y, Zhang F, Li H, Liao Y, Wei Z, Wan G, Xiang X, Hu M, Xia K, Chen X, Tang J (2015) Elevated mitochondrial DNA copy number in peripheral blood cells is associated with childhood autism. BMC Psychiatry 15: 50. http://doi.org/10.1186/s12888-0150432-y

Chinnery PF, Samuels DC (1999) Relaxed replication of mtDNA: A model with implications for the expression of disease. Am J Hum Genet 64: 1158-1165. http://doi.org/10.1086/302311

Chiu RWK, Chan LYS, Lam NYL, Tsui NBY, Ng EKO, Rainer TH, Dennis Lo YM (2003) Quantitative analysis of circulating mitochondrial DNA in plasma. Clin Chem 49: 719-726. http://doi. org/10.1373/49.5.719

Gonzalez-Hunt CP, Rooney JP, Ryde IT, Anbalagan C, Joglekar R, Meyer JN (2016) PCR-Based analysis of mitochondrial dna copy number, mitochondrial DNA damage, and nuclear DNA damage. Curr Protoc Toxicol 67: 20.11.1-20.11.25. http://doi. org/10.1002/0471140856.tx2011s67

Grady JP, Murphy JL, Blakely EL, Haller RG, Taylor RW, Turnbull DM, Tuppen HAL (2014) Accurate measurement of mitochondrial DNA deletion level and copy number differences in human skeletal muscle. PLoS One 9: e114462. http://doi.org/10.1371/journal. pone. 0114462

Greaves LC, Reeve AK, Taylor RW, Turnbull DM (2012) Mitochondrial DNA and disease. J Pathol 226: 274-286. http://doi.org/10.1002/ path.3028

Holloszy JO, Coyle EF (1984) Adaptations of skeletal muscle to endurance exercise and their metabolic consequences. J Appl Physiol 56: 831-838.

Huang J, Tan L, Shen R, Zhang L, Zuo H, Wang DW (2016) Decreased Peripheral mitochondrial DNA copy number is associated with the risk of heart failure and long-term outcomes. Medicine Baltimore) 95: e3323. http://doi.org/10.1097/MD.0000000000003323

Jedrak P, Krygier M, Tońska K, Drozd M, Kaliszewska M, Ewa B, Sołtan W, Sitek J. E, Stanislawska-Sachadyn A, Limon J, Sławek J, Węrzyn G, Barańska S (2017) Mitochondrial DNA levels in Huntington disease leukocytes and dermal fibroblasts. Metab Brain Dis 32: 1237-1247. http://doi.org/10.1007/s11011-017-0026-0

Kalinowski DP, Illenye S, Van Houten B (1992) Analysis of DNA damage and repair in murine leukemia L1210 cells using a quantitative polymerase chain reaction assay. Nucleic Acids Res 20: 34853494.

Lee H, Song J, Shin C, Park D, Park K, Lee K, Koh CS (1998) Decreased mitochondrial DNA content in peripheral blood precedes the development of non-insulin-dependent diabetes mellitus. Diabetes Res Clin Pract 42: 161-167. http://doi.org/10.1016/S01688227(98)00110-7

Lee HC, Yin PH, Lu CY, Chi CW, Wei YH (2000) Increase of mitochondria and mitochondrial DNA in response to oxidative stress in human cells. Biochem J 348 Pt 2: 425-432.

Liu CS, Cheng WL, Kuo SJ, Li JY, Soong BW, Wei YH (2008) Depletion of mitochondrial DNA in leukocytes of patients with poly-Q diseases. J Neurol Sci 264: 18-21. http://doi.org/10.1016/j. jns.2007.07.016

LO YMD (2006). Circulating nucleic acids in plasma and serum: an overview. Ann N Y Acad Sci 945: 1-7. http://doi. org/10.1111/j.1749-6632.2001.tb03858.x

Malik AN, Czajka A (2013) Is mitochondrial DNA content a potential biomarker of mitochondrial dysfunction? Mitochondrion 13: 481-492. http://doi.org/10.1016/j.mito.2012.10.011

Malik AN, Shahni R, Iqbal MM (2009) Increased peripheral blood mitochondrial DNA in type 2 diabetic patients with nephropathy. Diabetes Res Clin Pract 86: 22-24. http://doi.org/10.1016/j.diabres.2009.07.002

Masayesva BG, Mambo E, Taylor RJ, Goloubeva OG, Zhou S, Cohen Y, Minhas K, Koch W, Sciubba J, Alberg AJ, Sidransky D, Califano J (2006) Mitochondrial DNA content increase in response to cigarette smoking. Cancer Epidemiol Biomarkers Prev 15: 19-24. http://doi. org/10.1158/1055-9965.EPI-05-0210

Meissner C, Mohamed SA, Klueter H, Hamann K, von Wurmb N, Oehmichen M (2000) Quantification of mitochondrial DNA in human blood cells using an automated detection system. Forensic Sci Int 113: 109-112. https://doi.org/10.1016/S0379-0738(00)00249-8

Morten K, Ashley N, Wijburg F, Hadzic N, Parr J (2007) Liver mtDNA content increases during development: a comparison of methods and the importance of age-and tissue-specific controls for the diagnosis of mtDNA. Mitochondrion 7: 386-395. http://doi. org/10.1016/j.mito.2007.09.001 
Nicholls DG (2002) Mitochondrial bioenergetics, aging, and aging-related disease. Sci Aging Knowl Env 2002: 12. http://doi.org/10.1126/ sageke.2002.31.pe12

Petersen MH, Budtz-Jørgensen E, Sørensen SA, Nielsen JE, Hjermind LE, Vinther-Jensen T, Nielsen SMB, Nørremølle A (2014) Reduction in mitochondrial DNA copy number in peripheral leukocytes after onset of Huntington's disease. Mitochondrion 17: 14-21. http:// doi.org/10.1016/j.mito.2014.05.001

Pyle A, Anugrha H, Kurzawa-Akanbi M, Yarnall A, Burn D, Hudson G (2016) Reduced mitochondrial DNA copy number is a biomarker of Parkinson's disease. Neurobiol Aging 38: 216.e7-10. http://doi. org/10.1016/j.neurobiolaging.2015.10.033

Wallace DC (2010) Mitochondrial DNA mutations in disease and aging. Environ Mol Mutagen 51: 440-450. http://doi.org/10.1002/ em.20586

Weng SW, Lin TK, Liou CW, Chen SD, Wei YH, Lee HC, Chen IY, Hsieh CJ, Wang PW (2009) Peripheral blood mitochondrial DNA content and dysregulation of glucose metabolism. Diabetes Res Clin Pract 83: 94-99. http://doi.org/10.1016/j.diabres.2008.10.002

Wojtczak L, Zabocki K (2008) Basic mitochondrial physiology in cell viability and death. In Drug-Induced Mitochondrial Dysfunction. Dykens JA Will Y eds, John Wiley \& Sons. http://doi. org/10.1002/9780470372531.ch1

Wong J, McLennan SV, Molyneaux L, Min D, Twigg SM, Yue DK (2009) Mitochondrial DNA content in peripheral blood monocytes: relationship with age of diabetes onset and diabetic complications. Diabetologia 52: 1953-1961. http://doi.org/10.1007/s00125-0091424-6

Zhang H, Cooney DA, Sreenath A, Zhan Q, Agbaria R, Stowe EE, Fornace AJ, Johns DG (1994) Quantitation of mitochondrial DNA in human lymphoblasts by a competitive polymerase chain reaction method: application to the study of inhibitors of mitochondrial DNA content. Mol Pharmacol 46: 1063-1069. 